\title{
Does COVID-19 infection have an impact on children's psychological problems?
}

\author{
Gellan K. Ahmed ${ }^{1,2^{*}} \mathbb{0}$, Khaled Elbeh${ }^{1}$, Hamdy M. Gomaa ${ }^{3}$ and Saeed Soliman ${ }^{4}$
}

\begin{abstract}
Background: Coronavirus disease 2019 (COVID-19) has a significant impact on children, adolescents, and their families. So, the purpose of this study is to investigate the prevalence of children's psychological problems during the COVID-19 pandemic and their association of COVID-19 infection in children and their risk factors. A cross-sectional study was conducted on 148 children aged 6-12 years old categorized into 2 groups based on COVID-19 infection history. Participants were assessed by the Socioeconomic Scale and the Checklist for Children's Behavior (CBCL).

Results: Children who had COVID-19 had a high percentage of problems regarding family, school, social, financial, and parent problems due to the COVID-19 pandemic. Regarding CBCL, children who had COVID-19 infection had a higher percentage of clinical rating than the other group regarding withdrawal (11.1\% vs. 8.9\%), anxious/depressed (33.3\% vs. $25 \%)$, somatic (11.1\% vs. $10.7 \%)$, internalizing (61.1\% vs. $48.2 \%)$, externalizing (38.9\% vs. $35.7 \%)$, and total problems (50\% vs. 44.6\%). Family history of psychiatric disorder and the presence of three or more offspring were at high risk for internalizing problems, while those with school problems during pandemic were more vulnerable for internalizing and total problems.

Conclusion: Children with COVID-19 infection had a higher risk of developing psychological problems, such as withdrawal, anxiety/depression, somatic, internalizing, externalizing, and total problems.
\end{abstract}

Keywords: COVID-19, Children, Psychiatric comorbidity

\section{Background}

Coronavirus disease 2019 (COVID-19) has a significant impact on people all over the world. Isolation, contact limitations, and financial closure would all have a profound effect on the psychological environment of the impacted countries. Children, adolescence, and their families are severely affected by the current circumstances [1].

Children have a less chance of acquiring the severe form of the illness and need less hospitalization and mechanical breathing than adults [2]. However, children and adolescents may be particularly vulnerable to the pandemic's biopsychosocial stressors. The quarantine

\footnotetext{
*Correspondence: gillankaram@aun.edu.eg

${ }^{1}$ Department of Neurology and Psychiatry, Faculty of Medicine, Assiut

University, Assiut, Egypt

Full list of author information is available at the end of the article
}

strategy was activated to prevent virus spread. It disturbed people's daily life routines due to social isolation and difficulty in understanding the outbreak's short- and long-term consequences $[3,4]$.

During the COVID-19 pandemic, many factors impacted children and adolescents, including the closure of kindergartens and schools, the restriction of social contacts, and outdoor leisure activities. Parents were encouraged to help their children with home education while also working from home. Other family members' and social support systems' assistance has declined. Aside from worries and fears about COVID-19, the economic situation has deteriorated, escalating unemployment rates in all countries affected. This has placed a great stress on children, adolescents, and their families, potentially leading to distress, mental health issues, and violence [1]. 
COVID-19 pandemic consequences could be disastrous. As a child or adolescent's central nervous system (CNS) is in a susceptible developmental time, any stressful issues during crucial time can cause short- and long-term physiological $[5,6]$, cognitive, and behavioral damages [5, 7]. The amygdala, hippocampus, and prefrontal cortex are the specific brain areas that are related to stress. The response is mediated by a complex series of hormonal, immune, and neurotransmitter responses, which can alter glial cell response patterns and monoamine metabolism, resulting in cell apoptosis and psychiatric problems [5, 8].

People with COVID-19 infection may have psychiatric problems caused by biological factors other than psychosocial factors [9], such as inflammation which is linked to the pathogenesis of depression [10], schizophrenia [11], and bipolar disorder [12]. In addition to direct infection, blood circulation, neuronal involvement, hypoxic injury, immune injury, and angiotensin-converting enzyme 2 (ACE2) binding are the potential causes of CNS damage that trigger psychiatric problems in survivors [13].

So, the purpose of this study is to investigate the psychological problems of the COVID-19 pandemic in children aged 6 to 12 years old. Also, the impact of COVID-19 infection and the possible risk factors for these problems.

\section{Methods \\ Participants and procedures}

From February to May 2021, a cross-sectional study was conducted. A total of 148 children aged 6-12 years old were recruited from three Assiut government primary schools, Egypt. During this time, students were only allowed to attend school for 2 days a week, and most of their education was provided online. So, with the permission of the manager's school, we distributed an online Google form through school websites to invite parents to participate in our study to assess their children. The parents who accepted our invitation were interviewed with their children at Assiut University's Child Psychiatry Clinic, the Neurology and Psychiatric Hospital. Furthermore, the children were divided into two groups: the first group who had COVID-19 infection $(N=36)$ as documented with a PCR report, and the second group, who did not have COVID-19 infection $(n=112)$. Children with a history of mental disorders, a medical or neurological disease, or their intelligence quotient (IQ) below 70 were excluded from the study.

\section{Measures}

At the start of the study, participants were given a full psychiatric and medical history by semi-structured interview prepared by the researchers. Parents were asked about the previous infection of COVID-19 in their children with PCR report and the duration of the diagnosis.

\section{Sociodemographic data}

Sociodemographic data included age, gender, birth order, number of children, delivery type and problems, delay of speech development, delay of motor development, and family history of psychiatric disorders.

\section{The impact of COVID-19 pandemic on children life}

Information gathering include the impact of COVID-19 on children regarding (Did any one of the family (first relative degree) have a diagnosis as COVID-19 infection? (yes/no), Did any one of the family (first relative degree) die from COVID-19 infection? (yes/no), School problems (academic) due to COVID-19 infection? (yes/no), Social problems (peers) due to COVID-19 infection? (yes/no), Problems in parent relationship due to COVID-19 infection? (yes/no), Increase family expenses due to COVID19 infection? (yes/no), Decrease family income due to COVID-19 infection? (yes/no).

\section{The socioeconomic scale}

The socioeconomic scale [14] is a tool for determining social burdens and socioeconomic classes. It also includes four major variables: the father's and mother's educational levels, their respective occupations, the total family income, and the family's lifestyle.

\section{The checklist for children's behavior (CBCL)}

The CBCL [15] is a questionnaire with 113 items that parents fill out to help identify emotional and behavioral problems in children and adolescents aged 6 to 18. It is graded on a three-point Likert scale ranging from 0 (no response) to 2 (complete response) (occurs often). The items are rated based on the child's behavior over the previous 6 months.

\section{Statistical analysis}

SPSS was used to conduct the statistical analysis (version 26). As descriptive statistics, frequencies and percentages were reported. The categorical variables were evaluated using the Pearson chi-squared test. To detect the difference in mean values between the two groups, the independent $t$ test was used to assess quantitative variables. Researchers used multivariate logistic regressions to identify possible risk factors for externalizing, internalizing, and total problems in children. Statistical significance was defined as a probability value ( $p$ value) of less than 0.05 . 


\section{Results}

A total of 148 child were assessed and included in this study of them, the majority were males, first birth order, no postpartum problems, no delay in speech or motor development, no family history of psychiatric disorders, and belong to middle socioeconomic level (see Table 1). Regarding COVID-19 infection status, 36 had COVID19 infection as documented with a PCR report, while 112 did not have COVID-19 infection.

\section{Sociodemographic data}

Among the studied groups, there was a significant difference regarding age, speech development delay, and socioeconomic status. The mean age of children who had COVID-19 was $9.11 \pm 1.9$, while the mean age of children without COVID-19 infection was $8.13 \pm 1.7$. In the COVID-19 infection group, the mean time of diagnosis of COVID-19 infection was $2.13 \pm 1.5$ months before the interview.

Larger proportion of children who had COVID-19 (44.4\%) had delay of speech development compared to children without COVID-19 infection (26.8\%). Regarding the socioeconomic (SE) level, middle class was the prevailing in both groups. However, lager proportion of children who had COVID-19 was in the high SE class (22.2\%) in comparison to children without COVID-19 infection (7.1\%). Subsequently, children without COVID-19 infection had higher percentage of lower class (16.1\%) when compared to children with history of COVID-19 infection (11.1\%).

\section{The impact of COVID-19 pandemic on children life}

In Table 2, children who had COVID-19 were more affected by the COVID-19 pandemic in their life than children without COVID-19 infection regarding family member who got an infection or died from COVID-19; school, social, parent problems; increase family expenses; and decrease family income.

\section{$\mathrm{CBCL}$ result}

According to the CBCL scores, the percentage of children who had a clinical rating of the profile of syndromes during the COVID-19 pandemic were $9.5 \%$ of withdrawal; $13.5 \%$ of somatic complaints; $14.9 \%$ of social problems; $27 \%$ of anxious/depressed; $18.9 \%$ of thought problems; $54.1 \%$ of rules breaking behavior; $18.9 \%$ of aggressive behavior; $23 \%$ of depression problems; $24.3 \%$ of anxiety problems; $10.8 \%$ of somatic problems; $18.9 \%$ of oppositional defiant problems; $17.6 \%$ of conduct problems;

Table 1 Sociodemographic data of studied groups

\begin{tabular}{|c|c|c|c|c|}
\hline Variables & $\begin{array}{l}\text { Children had COVID-19 } \\
(N=36)\end{array}$ & $\begin{array}{l}\text { Children did not have COVID- } \\
19(n=112)\end{array}$ & $\begin{array}{l}\text { Total of participants }(N \\
=148)\end{array}$ & $P$ value \\
\hline Age (years) (mean \pm SD) & $9.11 \pm 1.9$ & $8.13 \pm 1.7$ & $8.36 \pm 1.8$ & $0.001^{*}$ \\
\hline \multicolumn{5}{|l|}{ Gender } \\
\hline Males & 20 (55.6\%) & 58 (51.8\%) & 78 (52.7\%) & \multirow[t]{2}{*}{0.7} \\
\hline Females & $16(44.4 \%)$ & $54(48.2 \%)$ & $70(47.3 \%)$ & \\
\hline \multicolumn{5}{|l|}{ Order of birth } \\
\hline First & $24(66.7 \%)$ & $82(73.2 \%)$ & $106(71.6 \%)$ & \multirow[t]{3}{*}{0.66} \\
\hline Second & $10(27.7 \%)$ & $22(19.6 \%)$ & $32(21.6 \%)$ & \\
\hline Third or more & $2(5.6 \%)$ & $8(7.1 \%)$ & $10(6.8 \%)$ & \\
\hline \multicolumn{5}{|l|}{ Number of children } \\
\hline Only child & $2(5.6 \%)$ & $8(7.1 \%)$ & $10(6.8 \%)$ & \multirow[t]{3}{*}{0.74} \\
\hline Two & $14(38.8 \%)$ & $36(32.1 \%)$ & $50(33.8 \%)$ & \\
\hline Three or more & $20(55.6 \%)$ & $68(60.7 \%)$ & $88(59.4 \%)$ & \\
\hline Pregnancy problems & $12(33.3 \%)$ & $10(8.9 \%)$ & $22(14.8 \%)$ & 0.33 \\
\hline Post-partum problems for children & $0(0 \%)$ & $4(3.6 \%)$ & $4(2.7 \%)$ & 0.32 \\
\hline Delay of speech development & $16(44.4 \%)$ & $30(26.8 \%)$ & $46(31.1 \%)$ & $0.039^{*}$ \\
\hline Delay of motor development & $2(5.6 \%)$ & $10(8.9 \%)$ & $12(8.1 \%)$ & 0.4 \\
\hline Family history of psychiatry disorders & $4(11.1 \%)$ & $20(17.9 \%)$ & $24(16.2 \%)$ & 0.24 \\
\hline \multicolumn{5}{|l|}{ Socioeconomic level } \\
\hline Low class & $4(11.1 \%)$ & $18(16.1 \%)$ & $22(14.9 \%)$ & \multirow[t]{3}{*}{$0.03^{*}$} \\
\hline Middle class & $24(66.7 \%)$ & $86(76.8 \%)$ & $110(74.3 \%)$ & \\
\hline High class & 8 (22.2\%) & $8(7.1 \%)$ & $16(10.8 \%)$ & \\
\hline
\end{tabular}

*Significant $p$ value 
Table 2 Association between COVID-19 infection status and areas of children's life

\begin{tabular}{|c|c|c|c|c|}
\hline Variables & $\begin{array}{l}\text { Children had COVID-19 } \\
(N=36)\end{array}$ & $\begin{array}{l}\text { Children did not have } \\
\text { COVID-19 }(n=112)\end{array}$ & $\begin{array}{l}\text { Total of participants } \\
(N=148)\end{array}$ & $P$ value \\
\hline $\begin{array}{l}\text { Did any one of the family (first relative degree) have } \\
\text { diagnosis as COVID-19 infection. }\end{array}$ & $36(100 \%)$ & $38(33.9 \%)$ & $74(50 \%)$ & $0.000^{*}$ \\
\hline $\begin{array}{l}\text { Did any one of the family (first relative degree) die from } \\
\text { COVID-19 infection. }\end{array}$ & $4(11.1 \%)$ & $6(5.4 \%)$ & $10(6.8 \%)$ & 0.2 \\
\hline School problems (academic) due to covid19 & $24(66.7 \%)$ & $72(64.3 \%)$ & $96(64.9 \%)$ & 0.48 \\
\hline Social problems (peers) due to COVID-19 & $31(86.1 \%)$ & $96(85.7 \%)$ & $127(85.8 \%)$ & 0.05 \\
\hline Problems in parent relationship due to COVID-19 & $28(77.7 \%)$ & $86(76.8 \%)$ & $114(77 \%)$ & 0.27 \\
\hline Increase family expenses due to COVID-19 & $14(38.9 \%)$ & $40(35.7 \%)$ & $54(36.5 \%)$ & 0.43 \\
\hline Decrease family income due to COVID-19 & $14(38.9 \%)$ & $38(33.9 \%)$ & $52(35.1 \%)$ & 0.36 \\
\hline
\end{tabular}

*Significant $p$ value

$51.4 \%$ of internalizing problems; $36.5 \%$ of externalizing problems; and $45.9 \%$ of total problems.

There was a significant difference regarding thought problems and rules breaking behavior between the studied groups. Children who had COVID-19 had a higher percentage of clinical rating than children without COVID-19 infection regarding withdrawal (11.1\% vs. $8.9 \%$ ), anxious/depressed ( $33.3 \%$ vs. $25 \%)$, internalizing problems (61.1\% vs. $48.2 \%)$, externalizing problems (38.9\% vs. $35.7 \%)$, and total problems (50\% vs. $44.6 \%$ ).

In addition, the CBCL Profile of DSM-5 scales had a higher percentage of clinical rating in children who had COVID-19 than without COVID-19 infection regarding depression problems (27.8\% vs. $21.4 \%$ ) and somatic problems (11.1\% vs. $10.7 \%$ ) (see Tables 3 and 4 ).

\section{Identification of the possible risk factors of psychiatric comorbidity of COVID-19 pandemic in children}

In Table 5, the multivariate logistic regression module regarding risk factors for externalizing, internalizing, and total problems of the studied groups. Surprisingly, none of the studied risk factors were associated with externalizing problems. Children with a family history of psychiatric disorder, and the presence of three or more offspring were more vulnerable to internalizing problems while children who had school problems during pandemic were more vulnerable to internalizing and total problems.

\section{Discussion}

The important findings in this study are a higher percentage of clinical rating in children who had COVID19 compared to children who did not have COVID-19 regarding internalizing problems $(61.1 \%$ vs. $48.2 \%)$, externalizing problems $(38.9 \%$ vs. $35.7 \%)$, and total problems $(50 \%$ vs. $44.6 \%)$. No identified risk factors were associated with externalizing problems. At the same time, children who had a family history of psychiatric disorder, and the presence of three or more offspring were more vulnerable to internalizing problems while children who had school problems during pandemic were more vulnerable for internalizing and total problems.

In the current study, children who had COVID19 were more frequent in speech development delay, belonged to a high socioeconomic level and more suffered regarding family members who got an infection or died from COVID-19; school, social, and parent problems; increase family expenses; and decrease family income than the other group.

Social contact plays a major role in development of cognition, emotions, attachment, and relationships [16]. Also, it helps in the physiological regulation of the body's responses to acute stressors [17]. Furthermore, Danese et al. (2009) found that childhood social isolation is a risk factor for depression in adulthood [5]. Since dysfunctional systemic inflammation has a role in impaired neurodevelopmental processes and causes cognitive and mood disturbances [18], it seems reasonable to assume that inflammatory changes in children exposed to COVID-19 infection could causes longterm physiological and psychological harm and should be a major concern [19].

Fear's influence on children and adolescents is another major source of concern. During COVID19 pandemic, a study about fear in the quarantined children and adolescents found a high prevalence of fear among the studied groups. This fear was primarily related to financial concerns, risk of COVID-19 infection, and infecting others [20]. Furthermore, it is unsurprising that adolescence is a stress-sensitive developmental period in terms of fear regulation, chronic stress has been shown to have a significant impact on amygdala prefrontal cortex connectivity and activity, impairing, for example, fear memory extinction 
Table 3 CBCL Profile of syndromes of studied groups

\begin{tabular}{|c|c|c|c|c|}
\hline Variables & $\begin{array}{l}\text { Children had COVID-19 ( } N \\
=36)\end{array}$ & $\begin{array}{l}\text { Children did not have COVID-19 } \\
(n=112)\end{array}$ & $\begin{array}{l}\text { Total of participants }(N= \\
\text { 148) }\end{array}$ & $P$ value \\
\hline \multicolumn{5}{|l|}{ Withdrawn } \\
\hline Normal & $26(72.2 \%)$ & $92(82.2 \%)$ & $118(79.7 \%)$ & \multirow[t]{3}{*}{0.37} \\
\hline Borderline & $6(16.7 \%)$ & $10(8.9 \%)$ & $16(10.8 \%)$ & \\
\hline Clinical rating & $4(11.1 \%)$ & $10(8.9 \%)$ & $14(9.5 \%)$ & \\
\hline \multicolumn{5}{|l|}{ Somatic complaints } \\
\hline Normal & $28(77.8 \%)$ & 80 (71.4\%) & $108(73 \%)$ & \multirow[t]{3}{*}{0.75} \\
\hline Borderline & $4(11.1 \%)$ & $16(14.3 \%)$ & $20(13.5 \%)$ & \\
\hline Clinical rating & $4(11.1 \%)$ & $16(14.3 \%)$ & $20(13.5 \%)$ & \\
\hline \multicolumn{5}{|l|}{ Social problems } \\
\hline Normal & $30(83.3 \%)$ & $90(80.3 \%)$ & $120(81 \%)$ & \multirow[t]{3}{*}{0.68} \\
\hline Borderline & $2(5.6 \%)$ & $4(3.6 \%)$ & $6(4.1 \%)$ & \\
\hline Clinical rating & $4(11.1 \%)$ & $18(16.1 \%)$ & $22(14.9 \%)$ & \\
\hline \multicolumn{5}{|l|}{ Anxious/depressed } \\
\hline Normal & $16(44.4 \%)$ & $62(55.4 \%)$ & $78(52.7 \%)$ & \multirow[t]{3}{*}{0.49} \\
\hline Borderline & $8(22.2 \%)$ & $22(19.6 \%)$ & 30 (20.3\%) & \\
\hline Clinical rating & $12(33.3 \%)$ & $28(25 \%)$ & $40(27 \%)$ & \\
\hline \multicolumn{5}{|l|}{ Thought problems } \\
\hline Normal & $30(83.3 \%)$ & $72(64.3 \%)$ & $102(68.9 \%)$ & \multirow[t]{3}{*}{$0.003^{*}$} \\
\hline Borderline & $0(0 \%)$ & $18(16.1 \%)$ & $18(12.2 \%)$ & \\
\hline Clinical rating & $6(16.7 \%)$ & $22(19.6 \%)$ & $28(18.9 \%)$ & \\
\hline \multicolumn{5}{|l|}{ Attention problems } \\
\hline Normal & $36(100 \%)$ & 104 (92.9\%) & $140(94.6 \%)$ & \multirow[t]{3}{*}{0.12} \\
\hline Borderline & $0(0 \%)$ & $8(7.1 \%)$ & $8(5.4 \%)$ & \\
\hline Clinical rating & $0(0 \%)$ & $0(0 \%)$ & $0(0 \%)$ & \\
\hline \multicolumn{5}{|c|}{ Rules breaking behavior } \\
\hline Normal & $14(38.9 \%)$ & $44(39.3 \%)$ & $58(39.2 \%)$ & \multirow[t]{3}{*}{$0.03^{*}$} \\
\hline Borderline & $6(16.7 \%)$ & $4(3.6 \%)$ & $10(6.8 \%)$ & \\
\hline Clinical rating & $16(44.4 \%)$ & $64(57.1 \%)$ & 80 (54\%) & \\
\hline \multicolumn{5}{|l|}{ Aggressive behavior } \\
\hline Normal & $24(66.7 \%)$ & $72(64.3 \%)$ & $96(64.9 \%)$ & \multirow[t]{3}{*}{0.25} \\
\hline Borderline & $8(22.2 \%)$ & $16(14.3 \%)$ & $24(16.2 \%)$ & \\
\hline Clinical rating & $4(11.1 \%)$ & $24(21.4 \%)$ & $28(18.9 \%)$ & \\
\hline \multicolumn{5}{|c|}{ General profile of problems } \\
\hline \multicolumn{5}{|c|}{ Internalizing problems } \\
\hline Normal & $8(22.2 \%)$ & $42(37.5 \%)$ & $50(33.8 \%)$ & \multirow[t]{3}{*}{0.23} \\
\hline Borderline & $6(16.7 \%)$ & $16(14.3 \%)$ & $22(14.9 \%)$ & \\
\hline Clinical rating & $22(61.1 \%)$ & $54(48.2 \%)$ & $76(51.3 \%)$ & \\
\hline \multicolumn{5}{|c|}{ Externalizing problems } \\
\hline Normal & $14(38.9 \%)$ & $54(48.2 \%)$ & $68(45.9 \%)$ & \multirow[t]{3}{*}{0.55} \\
\hline Borderline & $8(22.2 \%)$ & $18(16.1 \%)$ & $26(17.6 \%)$ & \\
\hline Clinical rating & $14(38.9 \%)$ & $40(35.7 \%)$ & $54(36.5 \%)$ & \\
\hline \multicolumn{5}{|l|}{ Total problems } \\
\hline Normal & $12(33.3 \%)$ & 44 (39.3\%) & $56(37.8 \%)$ & \multirow[t]{3}{*}{0.8} \\
\hline Borderline & $6(16.7 \%)$ & $18(16.1 \%)$ & $24(16.2 \%)$ & \\
\hline Clinical rating & $18(50 \%)$ & 50 (44.6\%) & 68 (45.9\%) & \\
\hline
\end{tabular}

*Significant $p$ value 
Table 4 CBCL Profile of DSM-5 scales of studied groups

\begin{tabular}{|c|c|c|c|c|}
\hline Variables & $\begin{array}{l}\text { Children had COVID-19 ( } N \\
=36)\end{array}$ & $\begin{array}{l}\text { Children did not have COVID-19 ( } n \\
=112 \text { ) }\end{array}$ & $\begin{array}{l}\text { Total of participants }(N= \\
\text { 148) }\end{array}$ & $P$ value \\
\hline \multicolumn{5}{|c|}{ Depression problems } \\
\hline Normal & $16(44.4 \%)$ & $66(59 \%)$ & $82(55.4 \%)$ & \multirow[t]{3}{*}{0.31} \\
\hline Borderline & $10(27.8 \%)$ & $22(19.6 \%)$ & $32(21.6 \%)$ & \\
\hline Clinical rating & $10(27.8 \%)$ & $24(21.4 \%)$ & $34(23 \%)$ & \\
\hline \multicolumn{5}{|l|}{ Anxiety problems } \\
\hline Normal & $18(50 \%)$ & $68(60.7 \%)$ & $86(58.1 \%)$ & \multirow[t]{3}{*}{$0.02^{*}$} \\
\hline Borderline & $12(33.3 \%)$ & $14(12.5 \%)$ & $26(17.6 \%)$ & \\
\hline Clinical rating & $6(16.7 \%)$ & $30(26.8 \%)$ & $36(24.3 \%)$ & \\
\hline \multicolumn{5}{|l|}{ Somatic problems } \\
\hline Normal & $28(77.8 \%)$ & $84(75 \%)$ & $112(75.7 \%)$ & \multirow[t]{3}{*}{0.88} \\
\hline Borderline & $4(11.1 \%)$ & $16(14.3 \%)$ & $20(13.5 \%)$ & \\
\hline Clinical rating & $4(11.1 \%)$ & $12(10.7 \%)$ & $16(10.8 \%)$ & \\
\hline \multicolumn{5}{|c|}{ Attention deficit/hyperactivity problems } \\
\hline Normal & $36(100 \%)$ & $104(92.9 \%)$ & $140(94.6 \%)$ & \multirow[t]{3}{*}{0.1} \\
\hline Borderline & $0(0 \%)$ & $8(7.1 \%)$ & $8(5.4 \%)$ & \\
\hline Clinical rating & $0(0 \%)$ & $0(0 \%)$ & $0(0 \%)$ & \\
\hline \multicolumn{5}{|c|}{ Oppositional defiant problems } \\
\hline Normal & $34(94.4 \%)$ & $82(73.2 \%)$ & $116(78.4 \%)$ & \multirow[t]{3}{*}{$0.009^{*}$} \\
\hline Borderline & $0(0 \%)$ & $4(3.6 \%)$ & $4(2.7 \%)$ & \\
\hline Clinical rating & $2(5.6 \%)$ & $26(23.2 \%)$ & $28(18.9 \%)$ & \\
\hline \multicolumn{5}{|c|}{ Conduct problems } \\
\hline Normal & $18(50 \%)$ & $72(64.2 \%)$ & $90(60.8 \%)$ & \multirow[t]{3}{*}{0.13} \\
\hline Borderline & $12(33.3 \%)$ & $20(17.9 \%)$ & $32(21.6 \%)$ & \\
\hline Clinical rating & $6(16.7 \%)$ & $20(17.9 \%)$ & $26(17.6 \%)$ & \\
\hline
\end{tabular}

*Significant $p$ value

[21]. So, more research would be needed to study the negative effects of fear on the developing brain during COVID-19 pandemic [19].

Also, school routines are important coping mechanisms for children and adolescent with psychiatric problems [22]. Moreover, absences from school have been linked to decreased physical activity, increased internet surfing, impaired sleep rhythm, and less nutritionally appropriate diets in children and adolescents [23].

Regarding socioeconomic level, low socioeconomic status (SES) has been consistently associated with adverse health outcomes and an increased risk of death [24-26]. According to cross-sectional studies, evidence suggests that inflammation and immunosenescence play a role as mediators in the relationship between socioeconomic status and health [27, 28]. Psychosocial stress such as adversity, trauma, or discrimination tends to have less self-mastery and social support [26, 29]. These stressors are thought to be a mediating factor in the poor health-low SES link. It may do so (at least in part) via weakened immune system [30, 31]. During the COVID-19 epidemic, lockdown curfews, self-isolation, social distance, and quarantine impacted total physical, mental, spiritual, and social well-being [32]. The current study reviewed a sample of children with COVID-19 to see if socioeconomic status (SES) was linked to immune function. Surprisingly, high socioeconomic children were more vulnerable to have COVID-19 infection.

In this study, according to CBCL, half of children with COVID-19 had psychiatric problems and had a higher percentage of clinical rating regarding withdrawal, anxious/depressed, somatic problems, internalizing problems, externalizing problems, and total problems than children who did not have COVID-19.

Two previous researches were done in China to evaluate psychiatric problems in children and adolescent, the first one was conducted on the quarantined children and adolescent and found them to have depressions, anxiety, or both while the second study was conducted during the pandemic and found symptoms of inattention, clinging, worry, and irritability [33, 34]. Another study was done in India to evaluate the quarantined children and adolescents, and found a high prevalence of psychological 
Table 5 Multivariate logistic regressions analysis of risk factors for internalizing, externalizing, and total problems in children

\begin{tabular}{|c|c|c|c|c|c|c|}
\hline \multirow[t]{2}{*}{ Variable } & \multicolumn{2}{|c|}{ Internalizing problems } & \multicolumn{2}{|c|}{ Externalizing problems } & \multicolumn{2}{|c|}{ Total problems } \\
\hline & $P$ value & Odds ratio & $P$ value & Odds ratio & $P$ value & Odds ratio \\
\hline \multicolumn{7}{|l|}{ Gender } \\
\hline Females $^{\mathrm{a}}$ & 0.159 & 2.867 & 0.233 & 0.561 & 0.426 & 0.732 \\
\hline Having COVID-19 infection & 0.860 & 1.158 & 0.798 & 1.189 & 0.802 & 0.836 \\
\hline \multicolumn{7}{|l|}{ Number of children ${ }^{b}$} \\
\hline Two & 0.868 & 0.777 & 0.283 & 3.141 & 0.114 & 6.523 \\
\hline Three or more & $0.000^{*}$ & 15.858 & 0.280 & 1.731 & 0.148 & 2.212 \\
\hline \multicolumn{7}{|l|}{ Order of birthc } \\
\hline Second & 0.051 & 0.093 & 0.232 & 2.929 & 0.144 & 0.201 \\
\hline Third or more & 0.099 & 0.119 & 0.733 & 0.720 & 0.131 & 0.172 \\
\hline Delay of speech development & 0.066 & 0.305 & 0.139 & 0.440 & 0.186 & 0.465 \\
\hline Delay of motor development & 0.898 & 1.154 & 0.175 & 4.043 & 0.064 & 9.274 \\
\hline Family history of psychiatric disorders & $0.013^{*}$ & 1.051 & 0.936 & 0.947 & 0.989 & 1.010 \\
\hline Total score of socioeconomic level & 0.090 & 0.469 & 0.182 & 0.593 & 0.127 & 0.522 \\
\hline Have family infection & 0.053 & 0.222 & 0.160 & 0.441 & 0.670 & 1.300 \\
\hline Have died family member & 0.496 & 2.040 & 0.747 & 0.715 & 0.354 & 0.368 \\
\hline School problems & $0.004^{*}$ & 1.122 & 0.067 & 1.366 & $0.033^{*}$ & 1.274 \\
\hline Social problems & 0.346 & 2.274 & 0.878 & 0.904 & 0.446 & 1.795 \\
\hline Problems in parent relationship & 0.105 & 4.532 & 0.829 & 1.128 & 0.609 & 1.368 \\
\hline Increase family expenses & 0.413 & 0.460 & 0.068 & 0.260 & 0.074 & 0.190 \\
\hline Decrease family income & 0.178 & 0.305 & 0.167 & 2.552 & 0.467 & 1.775 \\
\hline
\end{tabular}

distress associated with experienced feelings of helplessness, worry, and fear [20].

A literature review reported the impacts of COVID19 pandemic stressors on children and adolescents' life. The COVID-19 pandemic stressor caused dysregulation in hypothalamic-pituitary-adrenal (HPA) axis by having inflammatory mediators' synthesis and release, e.g., proinflammatory cytokines, neurotransmitters, hormones, and other molecules that can interfere with different physiological mechanisms during the early stages of life when the child or adolescent is exposed to situations of long-term stress. This imbalance could be linked to immune, endocrine, and nervous system overload and the risk of developing psychiatric disorders later in life. The possible short-term effects of exposure to COVID-19 pandemic stressors at this stage of life were distress and hopelessness, irregular food intake, abuse and trauma, interpersonal and environmental restraint, sensory deprivation, and neglect. In contrast, the possible long-term consequences were underdeveloped brain circuitry, obesity, etc. [19].

This study has a few important implications for policymakers, which may be applied to enhance families' support with COVID-19 infection, as the infected children suffer more and are at an increased risk of developing psychiatric problems. As a result, psychiatric screening for children should be recommended, especially after infection with COVID-19. Psychoeducational programs are required to raise school, family, and community awareness of those children.

The current study had some limitations, including small sample size. As a result, we recommend that future studies with large representative samples to be conducted to confirm our findings. In addition, because most of the children were treated at home, we were unable to investigate the link between the severity of COVID-19 infection according to WHO guidelines [35] and psychological problems in children. Finally, due to the survey's crosssectional design, it was difficult to investigate causal relationships between variables. As a result, a longitudinal study should be considered.

\section{Conclusion}

Children infected with COVID-19 had a higher risk of developing psychological problems, such as withdrawal, anxiety/depression, somatic problems, internalizing 
problems, externalizing problems, and total problems. Furthermore, they were more affected by the COVID-19 pandemic in terms of family member infection or death from COVID-19; school, social, and parent problems; increased family expenses; and decreased family income than children who did not have with COVID-19. Also, children with a family history of psychiatric disorder, school problems, and the presence of three or more offspring were more vulnerable to internalizing problems while children who had school problems were more vulnerable to total problems.

\section{Abbreviations}

COVID-19: Coronavirus disease 2019; CNS: Central nervous system; ACE2: Angiotensin-converting enzyme 2; IQ: Intelligence quotient; CBCL: The Checklist for Children's Behavior; SES: Socioeconomic status.

\section{Acknowledgements}

None.

\section{Authors' contributions}

GA and SS recruited participants, analysis, and interpreted data, and were the contributors in writing the manuscript. KE and $\mathrm{HG}$ revised data interpretation, read and approved the final manuscript. The author(s) read and approved the final manuscript.

\section{Funding}

This research did not receive any specific grant from funding agencies in the public, commercial, or not-for-profit sectors.

\section{Availability of data and materials}

All data generated or analyzed during this study are available from the corresponding author on reasonable request.

\section{Declarations}

\section{Ethics approval and consent to participate}

The study received ethical approval from Assiut University, Faculty of Medicine's institutional review board (IRB). This research was registered as Clinical Trail Registered with Number (NCT04745819) registered on date 9 February 2021, https://clinicaltrials.gov/ct2/show/NCT04745819. To participate in the study, the parents signed informed consent on behalf of their children. They were assured that their information would be kept private, and that data would be made available in an anonymized form. All procedures performed in this study were in accordance with the ethical standard of the institution and/or national research committee, with the 1964 Helsinki Declaration and its later amendments.

\section{Consent for publication}

Not applicable.

\section{Competing interests}

The authors declare that they have no competing interests.

\begin{abstract}
Author details
${ }^{1}$ Department of Neurology and Psychiatry, Faculty of Medicine, Assiut University, Assiut, Egypt. ${ }^{2}$ Department of Child and Adolescent Psychiatry, Institute of Psychiatry, Psychology and Neuroscience, King's College London, London SE5 8AF, UK. ${ }^{3}$ Department of Family Medicine, Faculty of Medicine, Assiut University, Assiut, Egypt. ${ }^{4}$ Department of Family Medicine, Faculty of Medicine, Cairo University, Cairo, Egypt.
\end{abstract}

Received: 13 September 2021 Accepted: 15 October 2021 Published online: 27 October 2021

\section{References}

1. Fegert JM, Vitiello B, Plener PL, Clemens V (2020) Challenges and burden of the coronavirus 2019 (COVID-19) pandemic for child and adolescent mental health: a narrative review to highlight clinical and research needs in the acute phase and the long return to normality. Child Adolesc Psychiatry Ment Health 14:20. https://doi.org/10.1186/s13034-020-00329-3

2. She J, Liu L, Liu W (2020) COVID-19 epidemic: disease characteristics in children. J Med Virol 92(7):747-754. https://doi.org/10.1002/jmv.25807

3. Spinelli M, Lionetti F, Pastore M, Fasolo M (2020) Parents' stress and children's psychological problems in families facing the COVID-19 outbreak in Italy. Front Psychol 11:1713. https://doi.org/10.3389/fpsyg.2020.01713

4. Crescentini C, Feruglio S, Matiz A, Paschetto A, Vidal E, Cogo P et al (2020) Stuck outside and inside: an exploratory study on the effects of the COVID-19 outbreak on Italian parents and children's internalizing symptoms. Front Psychol 11:2850. https://doi.org/10.3389/fpsyg.2020.586074

5. Danese A, Moffitt TE, Harrington H, Milne BJ, Polanczyk G, Pariante CM et al (2009) Adverse childhood experiences and adult risk factors for agerelated disease: depression, inflammation, and clustering of metabolic risk markers. Arch Pediatr Adolesc Med 163(12):1135-1143. https://doi. org/10.1001/archpediatrics.2009.214

6. Gunnar M, Quevedo K (2007) The neurobiology of stress and development. Annu Rev Psychol 58(1):145-173. https://doi.org/10.1146/annurev. psych.58.110405.085605

7. Nugent NR, Tyrka AR, Carpenter LL, Price LH (2011) Gene-environment interactions: early life stress and risk for depressive and anxiety disorders. Psychopharmacology 214(1):175-196. https://doi.org/10.1007/ s00213-010-2151-x

8. Calcia MA, Bonsall DR, Bloomfield PS, Selvaraj S, Barichello T, Howes OD (2016) Stress and neuroinflammation: a systematic review of the effects of stress on microglia and the implications for mental illness. Psychopharmacology 233(9):1637-1650. https://doi.org/10.1007/s00213-016-4218-9

9. Wang Q, Xu R, Volkow ND (2021) Increased risk of COVID-19 infection and mortality in people with mental disorders: analysis from electronic health records in the United States. World Psychiatry 20(1):124-130. https://doi. org/10.1002/wps.20806

10. Beurel E, Toups M, Nemeroff CB (2020) The bidirectional relationship of depression and inflammation: double trouble. Neuron 107(2):234-256. https://doi.org/10.1016/j.neuron.2020.06.002

11. Müller N (2018) Inflammation in schizophrenia: pathogenetic aspects and therapeutic considerations. Schizophr Bull 44(5):973-982. https://doi.org/ 10.1093/schbul/sby024

12. Benedetti F, Aggio V, Pratesi ML, Greco G, Furlan R (2020) Neuroinflammation in bipolar depression. Front Psychiatry 11:71. https://doi.org/10.3389/ fpsyt.2020.0007

13. Troyer EA, Kohn JN, Hong S (2020) Are we facing a crashing wave of neuropsychiatric sequelae of COVID-19? Neuropsychiatric symptoms and potential immunologic mechanisms. Brain Behav Immun 87:34-39. https://doi.org/10.1016/j.bbi.2020.04.027

14. Abdel-Tawab MA (2010) Socioeconomic scale for family, revised edition. MD Thesis Educ Basics Faculty of Education, Assiut University 3:32-55

15. Achenbach T, Rescorla L (2001) Manual for the ASEBA school-age forms \& profiles: an integrated system of multi-informant assessment. University of Vermont. Research Center for Children, Youth, \& Families, Burlington, $p$ 1617

16. Cascio CJ, Moore D, McGlone F (2019) Social touch and human development. Dev Cogn Neurosci 35:5-11. https://doi.org/10.1016/j.dcn.2018.04. 009

17. Gallace A, Spence C (2010) The science of interpersonal touch: an overview. Neurosci Biobehav Rev 34(2):246-259. https://doi.org/10.1016/j. neubiorev.2008.10.004

18. Jiang NM, Cowan M, Moonah SN, Petri WA Jr (2018) The impact of systemic inflammation on neurodevelopment. Trends Mol Med 24(9):794804. https://doi.org/10.1016/j.molmed.2018.06.008

19. de Figueiredo CS, Sandre PC, Portugal LCL, Mázala-de-Oliveira T, da Silva Chagas L, Raony ĺ et al (2021) COVID-19 pandemic impact on children and adolescents' mental health: biological, environmental, and social factors. Prog Neuropsychopharmacol Biol Psychiatry 106:1 10171. https:// doi.org/10.1016/j.pnpbp.2020.110171

20. Saurabh K, Ranjan S (2020) Compliance and psychological impact of quarantine in children and adolescents due to COVID-19 
pandemic. Indian Pediatr 87(7):532-536. https://doi.org/10.1007/ s12098-020-03347-3

21. Tottenham N, Galván A (2016) Stress and the adolescent brain: amygdalaprefrontal cortex circuitry and ventral striatum as developmental targets. Neurosci Biobehav Rev 70:217-227. https://doi.org/10.1016/j.neubiorev. 2016.07.030

22. Kim SJ, Kim HJ, Jeon JY, Kim HW, Lee SA (2020) Clinical factors associated with suicide risk independent of depression in persons with epilepsy. Seizure 80:86-91. https://doi.org/10.1016/j.seizure.2020.05.026

23. Wang G, Zhang Y, Zhao J, Zhang J, Jiang F (2020) Mitigate the effects of home confinement on children during the COVID-19 outbreak. Lancet 395(10228):945-947. https://doi.org/10.1016/S0140-6736(20)30547-X

24. Adams P, Hurd MD, McFadden D, Merrill A, Ribeiro T (2003) Healthy, wealthy, and wise? Tests for direct causal paths between health and socioeconomic status. J Econom 112(1):3-56. https://doi.org/10.1016/ S0304-4076(02)00145-8

25. Mackenbach JP, Looman CWN, Artnik B, Bopp M, Deboosere P, Dibben C et al (2017)'Fundamental causes' of inequalities in mortality: an empirical test of the theory in 20 European populations. Sociol Health IIIn 39(7):1117-1133. https://doi.org/10.1111/1467-9566.12562

26. Cutler D, Deaton A, Lleras-Muney A (2006) The determinants of mortality. J Econ Perspect 20(3):97-120. https://doi.org/10.1257/jep.20.3.97

27. Dowd JB, Haan MN, Blythe L, Moore K, Aiello AE (2008) Socioeconomic gradients in immune response to latent infection. Am J Epidemiol 167(1):112-120. https://doi.org/10.1093/aje/kwm247

28. Dowd JB, Aiello AE, Alley DE (2009) Socioeconomic disparities in the seroprevalence of cytomegalovirus infection in the US population: NHANES III. Epidemiol Infect 137(1):58-65. https://doi.org/10.1017/S095026880 8000551

29. Thoits PA (2010) Stress and health: major findings and policy implications. J Health Soc Behav 51(Suppl):S41-S53. https://doi.org/10.1177/00221 46510383499
30. McEwen BS (2008) Central effects of stress hormones in health and disease: understanding the protective and damaging effects of stress and stress mediators. Eur J Pharmacol 583(2-3):174-185. https://doi.org/10. 1016/j.ejphar.2007.11.071

31. Glei DA, Goldman N, Chuang YL, Weinstein M (2007) Do chronic stressors lead to physiological dysregulation? Testing the theory of allostatic load. Psychosom Med 69(8):769-776. https://doi.org/10.1097/PSY.0b013e3181 $57 \mathrm{cba} 6$

32. Poudel K, Subedi P (2020) Impact of COVID-19 pandemic on socioeconomic and mental health aspects in Nepal. Int J Soc Psychiatry 66(8):748-755. https://doi.org/10.1177/0020764020942247

33. Chen F, Zheng D, Liu J, Gong Y, Guan Z, Lou D (2020) Depression and anxiety among adolescents during COVID-19: a cross-sectional study. Brain Behav Immun 88:36-38. https://doi.org/10.1016/j.bbi.2020.05.061

34. Jiao WY, Wang LN, Liu J, Fang SF, Jiao FY, Pettoello-Mantovani M et al (2020) Behavioral and emotional disorders in children during the COVID19 epidemic. J Pediatr 221:264-6.e1. https://doi.org/10.1016/j.jpeds.2020. 03.013

35. World Health Organization. (2020). Clinical management of severe acute respiratory infection (SARI) when COVID-19 disease is suspected: interim guidance, 13 March 2020. Retrieved from Geneva: https://apps.who.int/ iris/handle/10665/331446.

\section{Publisher's Note}

Springer Nature remains neutral with regard to jurisdictional claims in published maps and institutional affiliations.

\section{Submit your manuscript to a SpringerOpen ${ }^{\circ}$ journal and benefit from:}

- Convenient online submission

- Rigorous peer review

- Open access: articles freely available online

- High visibility within the field

- Retaining the copyright to your article

Submit your next manuscript at $\boldsymbol{\nabla}$ springeropen.com 